\title{
Comparative Study of the Cooling Energy Performance of Variable Refrigerant Flow Systems and Variable Air Volume Systems in Office Buildings
}

\author{
Xinqiao $\mathrm{Yu}^{1}$, Da Yan ${ }^{1,}{ }^{*}$, Kaiyu Sun ${ }^{2}$, Tianzhen Hong ${ }^{2}$, Dandan $\mathrm{Zhu}^{3}$ \\ ${ }^{1}$ School of Architecture, Tsinghua University, China \\ ${ }^{2}$ Building Technology and Urban Systems Division, Lawrence Berkeley National Laboratory, USA \\ ${ }^{3}$ Beijing Institute of Architectural Design, China \\ *Corresponding author (D. Yan), yanda@tsinghua.edu.cn.
}

\begin{abstract}
:
Variable air volume (VAV) and variable refrigerant flow (VRF) systems are widely used in office buildings. This study investigated VAV and VRF systems in five typical office buildings in China, and compared their cooling energy use. Site survey and field measurements were conducted to collect the data of building characteristics and operation. Measured cooling electricity use was collected from sub-metering in the five buildings. The sub-metering data normalized by climate and operating hours indicated that the cooling energy consumed by VRF systems was up to $70 \%$ lower than that consumed by VAV systems. This was mainly because of the different operation modes of both system types that led to significantly fewer operating hours for the VRF systems. Building simulations were used to quantify the impact of operation modes of VRF and VAV systems on cooling loads. A prototype office building in China was used as the model. The simulation results showed that the VRF operation mode required much lower cooling load when compared to the VAV operation mode. For example, the cooling loads decreased by $42 \%$ in Hong Kong and 53\% in Qingdao. The key findings include the following: the VRF systems operated in the part-time-part-space mode enabling occupants to turn on the air-conditioning only when needed and when the spaces were occupied. However, the VAV systems operated in the full-time-full-space mode limiting occupants' control of operation. These findings provide insights into VRF systems operation and controls as well as their energy performance, which could help guide HVAC designers on system selection and building operators or facility managers on system operations to achieve low- or zero-net energy buildings.
\end{abstract}

Keywords: Variable refrigerant flow (VRF) systems; variable air volume (VAV) systems; field measurement; building simulation; energy performance; comparative analysis 


\section{Introduction and Background}

The energy consumed by the building sector accounts for more than $30 \%$ of the total energy worldwide [1], and has exceeded the industrial and transportation sectors in developed countries [2][3][4]. In developed countries, heating, ventilation, and air-conditioning (HVAC) account for almost half of the total energy use in commercial buildings. The growing demand for improved thermal comfort in the building environment led to the wide spread implementation of HVAC systems, which caused a steady increase in building energy use [5][6]. Therefore, it is crucial to improve the energy performance of HVAC systems in order to reduce building energy and carbon emissions [7][8][9][10][11].

Variable air volume (VAV) systems are air systems that vary their supply air volume flow rate. This mechanism satisfies different space heating/cooling loads, maintains predetermined space air temperature and humidity for thermal comfort, and conserves fan power during part-load operations [12]. VAV systems satisfy indoor air quality (IAQ) requirements by supplying a minimum amount of outdoor air based on national regulations and standards [13]. There are two types of VAV systems, namely packaged VAV using direct-expansion cooling coils, and central VAV using chilled-water cooling coils. Many VAV systems supply air with a constant temperature and recirculate a portion of the returned air[14]. The VAV systems usually rely on the reheating at zone terminal units to meet zone comfort requirements at part-load conditions. The VAV system is the most typical HVAC system in office buildings. According to the Advanced Variable Air Volume System Design Guide by the California Energy Commission (2003), approximately half of the newly constructed large office buildings will utilize VAV reheat systems between 2003 and 2012 [15].

Variable Refrigerant Flow (VRF) systems are refrigerant systems, which are generally comprised of an outdoor unit serving multiple indoor units connected by a refrigerant piping network. There are two common VRF types, namely the heat pump type and the heat recovery type. The heat pump type VRF system only supplies cooling or heating at a time, but the heat recovery type VRF system supplies both cooling and heating simultaneously. Thus, VRF systems can be categorized into air-cooled and water-cooled groups depending on the cooling source for the outdoor condensers. The VRF system varies the refrigerant flow using variable speed compressors in the outdoor unit and electronic expansion valves (EEVs) located in each indoor unit. Advanced VRF systems can modulate the evaporating temperatures to meet the cooling loads of indoor units [16]. The ability of VRF systems to control the refrigerant mass flow rate according to cooling and/or heating loads has enabled the integration of as many as 60 indoor units with varied capacities using a single outdoor unit with one or multiple compressors. This unlocked the possibility of the zone level individual comfort control, with simultaneous heating and cooling in different zones, and heat recovery from one zone to another [17][18]. Given the extraordinary performances of individual and flexible zone level controls, the VRF systems have emerged as a great solution for applications requiring individualized comfort conditioning. 
Hence, VRF systems have gained much attention and are becoming more widely used with sales booming worldwide [19][20].

As an emerging HVAC technology, VRF systems were comprehensively compared with conventional HVAC systems, such as VAV systems, fan coil systems, and packaged ducted systems. A simulation study on a prototypical ten-story office building in Shanghai China showed that the VRF systems saved $22.2 \%$ and $11.7 \%$ energy when compared with central VAV systems and fan coil systems, respectively [21]. The energy performance of a VRF system was compared with a ground source heat pump (GSHP) system based on the simulation of a small office building in EnergyPlus [22]. The results indicated that the GSHP system was more efficient than the VRF system especially in cold climates, but there were no observed significant differences in the climates with modest heating loads. A VRF system serving the first floor and GSHP system serving the second floor were installed at ASHRAE Headquarter in Atlanta, Georgia in the USA. Their energy performances were measured and compared. The field test results showed that the GSHP system consumed approximately $20 \%$ and $60 \%$ less energy than the VRF system in the summer and winter/shoulder seasons, respectively [23]. The two tested two floors had different thermal loads due to the different space types (the first floor contained conference rooms, while the second floor contained offices), such as window-to-wall ratios, and user behaviors. Hence, the comparison of the two systems was not valid. Subsequent studies included a one-to-one performance matching and comparison. For an existing office building in Maryland, USA, simulations showed the VRF systems energy savings to range from $27.1 \%$ to $57.9 \%$ when compared with central VAV systems depending on the system configurations and design conditions [24]. It was observed that the VRF systems consumed $35 \%$ less energy than the central chiller/boiler-based systems under humid subtropical climate conditions [18], and consumed $30 \%$ less energy than the chiller-based systems under tropical climate conditions [25]. The actual savings from the VRF systems varied depending on several factors including climate, operation conditions, and control strategies [26][27]. From the thermal comfort viewpoint, the individual control feature of the VRF system enabled adjustment of the thermostat settings according to the specific preferences of different users, and thus improved the thermal satisfaction [28][29]. This was illustrated by a field-performance test of two different control modes (individual and master modes) that were applied to the VRF system of the test building [29]. Therefore, the VRF system consumed less energy than common air conditioning systems, and provided better indoor thermal comfort due to its independent and flexible zoning controls.

In the current literature, numerical simulations are predominantly used to compare different HVAC systems [30][31]. In this case, the simulation inputs were primarily from HVAC specifications and assumptions. There was no research that identified key factors leading to energy consumption discrepancies based on detailed field investigations in real buildings. Additionally, there was no research that further quantified the influence of factors. This study investigated 11 buildings using VRF systems or chiller-based central VAV systems in five Chinese cities, namely Beijing, Qingdao, Hangzhou, Shanghai, and Hong Kong to address this gap in 
knowledge. As a result, the large discrepancies of cooling energy consumption between VRF systems and VAV systems were confirmed in this study. As indicated by Fig 1, the VRF system consumed much less annual energy than the VAV system regardless of the climate zones. The impact of the VRF system will be further analyzed in Section 2. Among the 11 investigated buildings, five buildings (two using VRF, and three using VAV) contained more detailed survey information and sub-metered energy data. They were chosen for further comparison and analysis to indicate the key influencing factors of energy use discrepancy, and their influence was quantified using building simulations.

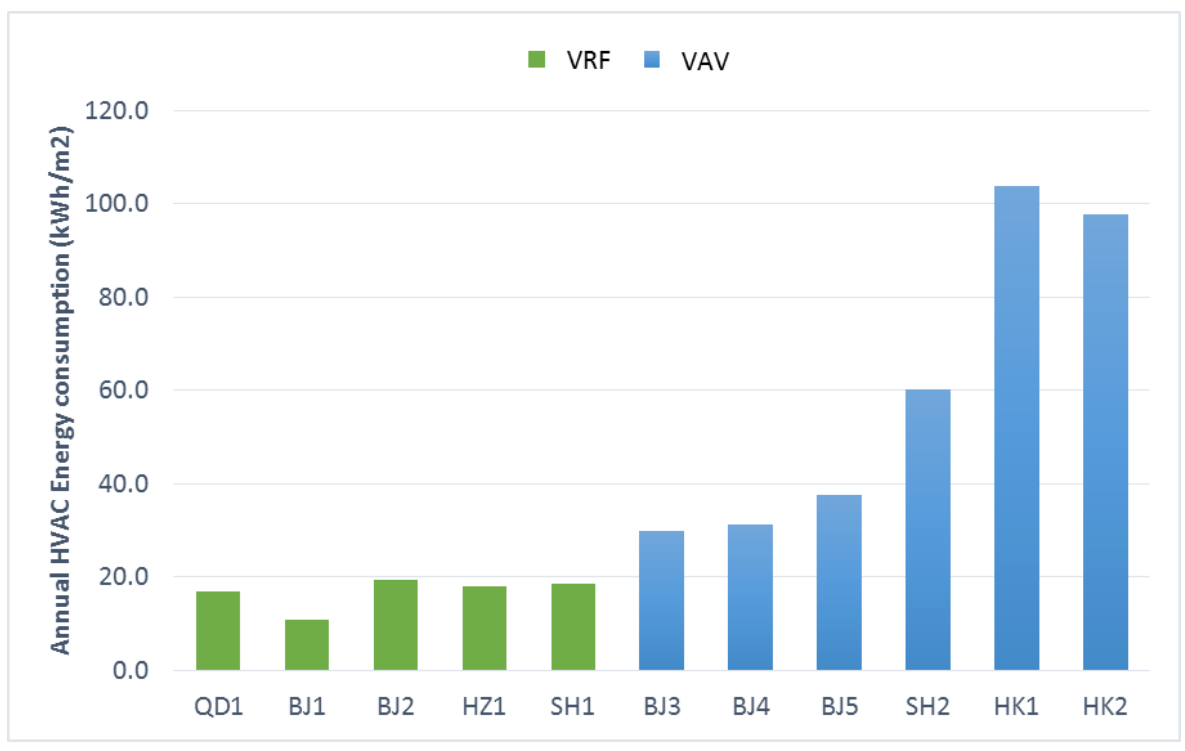

Fig 1. Annual HVAC energy consumption of the 11 investigated buildings

Notes: QD: Qingdao, BJ: Beijing, HZ: Hangzhou, SH: Shanghai, HK: Hong Kong.

In this study, heating system energy use excluded mainly due to the different heating systems that were used in the five selected buildings. It was observed that the buildings in Beijing and Qingdao used district heating, the buildings in Hangzhou used VRF heating, no heating wa used in Hong Kong. Hence, the heating energy use of these buildings could not be compared.

With respect to the building simulation, there were a limited number of simulation tools that could model VRF systems; among these were EnergyPlus and Trace 700. A previous study developed and used a customized version of EnergyPlus for a few simulation studies on VRF systems [21][24][32][33]. However, this special version was not available to the public and it was not verified or adopted by the EnergyPlus development team. In 2015, a new VRF heat pump model was developed, validated, and implemented in EnergyPlus by LBNL, and the new VRF model was available in EnergyPlus version 8.4 [34]. The designer's simulation toolkit (DeST) [35][36][37][38], developed by Tsinghua University, also had the ability to simulate the VRF system [39]. In our study, DeST was adopted as the simulation tool. 


\section{Methodology}

The discrepancies in the energy consumption of VRF and VAV systems were caused by differences in the HVAC system efficiencies, and by other factors such as climate, building envelope properties, operation schedules, and occupant behaviors[40][41][42].

The study involved field investigations and simulations. Field investigations in the five selected buildings included site surveys, field measurements, and sub-metering data, and were used to identify the main influencing factors. Numerical simulation was used to analyze the sensitivity and quantify the impact of the individual influencing factors on the energy performance. Figure 1 shows the overall methodology used in this study.

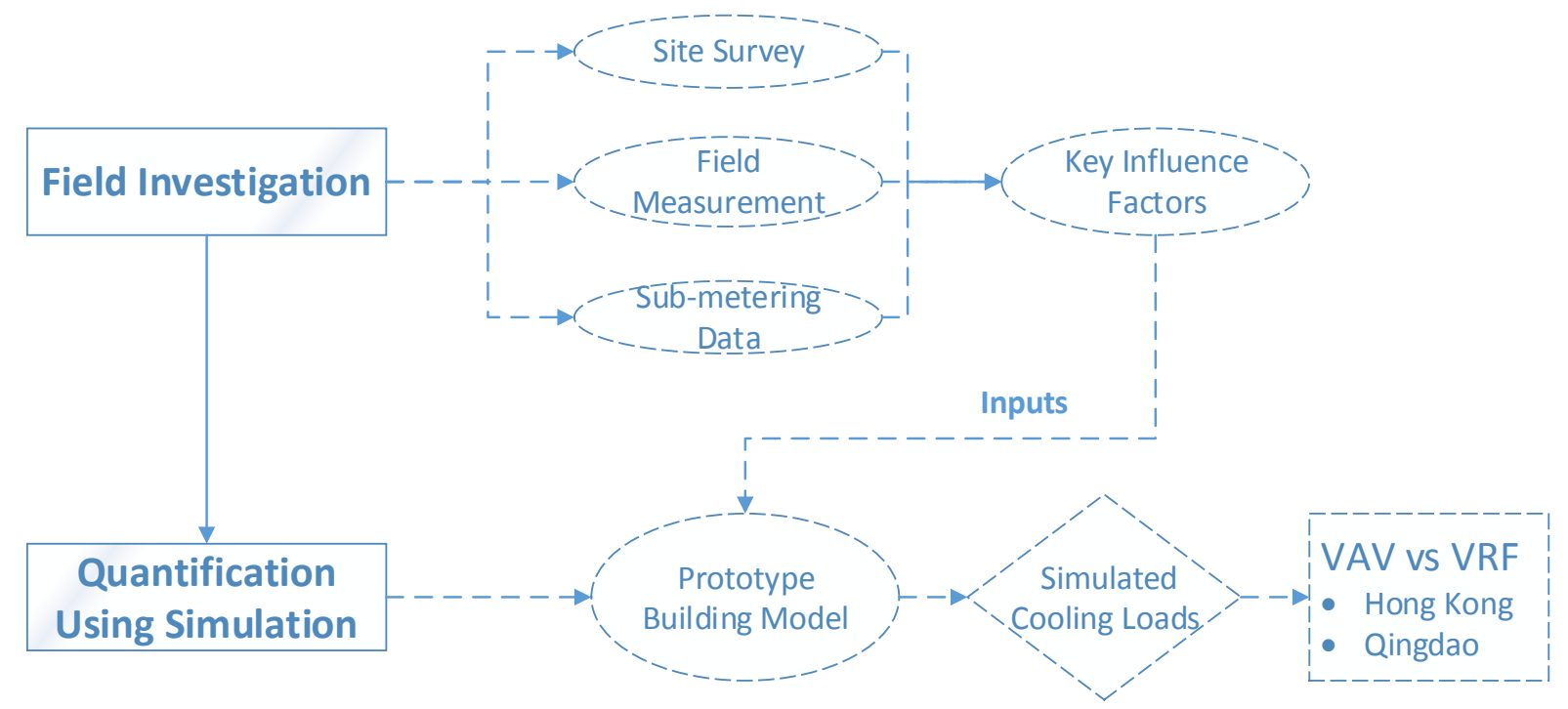

Figure 1 Overall Methodology

\subsection{Building Selection}

Five of the eleven investigated office buildings (Fig 1) were selected for further comparison and analysis for the following reasons: (1) they were located in different climate zones in China, (2) they contained detailed survey information and sub-metered energy use data, and (3) their air conditioning systems were either VAV systems or VRF systems for the purpose of comparison. Images of each of the five buildings are shown in Figure 2. Three of the buildings (C, D, and E) used chiller-based central VAV systems, while the other two (A and B) used air-cooled VRF systems. 




Building $\mathrm{A}: \mathrm{HZ}$

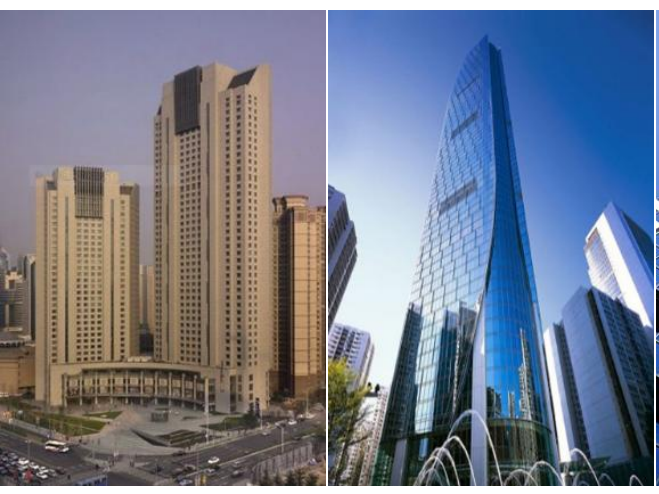

Building B: QD

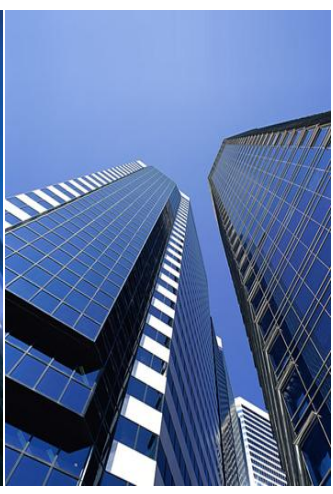

Building D: HK

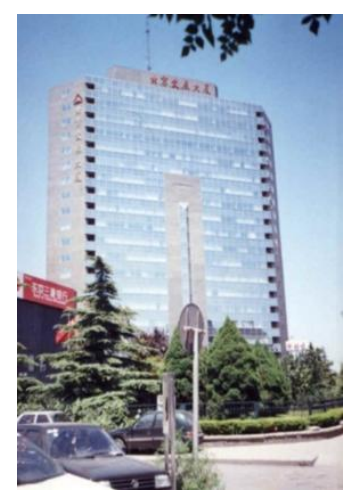

Building E: BJ

Figure 2 the five investigated buildings

Table 1 summarizes the characteristics of the five investigated buildings. Table 2 summarizes the envelope properties of the investigated buildings. Table 3 summarizes their HVAC systems. They were all high-rise large office buildings. All the buildings except Building $E$ were built between 2003 and 2008. Building $E$ in Beijing was built in 1990. Buildings $C$ and D were located in Hong Kong, which is much warmer than the other three locations.

Table 1 Summary of the five investigated buildings

\begin{tabular}{|c|c|c|c|c|c|}
\hline Buildings & $\begin{array}{c}\text { Location/ } \\
\text { Climate Zones }\end{array}$ & $\begin{array}{l}\text { ASHRAE } \\
\text { Climate } \\
\text { Zones }\end{array}$ & $\begin{array}{l}\text { Cooling } \\
\text { Degree } \\
\text { Days (CDD) }\end{array}$ & $\begin{array}{l}\text { Air-conditioned } \\
\text { Floor Area } \\
\left(\mathrm{m}^{2}\right)\end{array}$ & $\begin{array}{l}\text { Year } \\
\text { Built }\end{array}$ \\
\hline A & $\begin{array}{c}\text { Hangzhou /Hot } \\
\text { Summer Cold } \\
\text { Winter }\end{array}$ & $3 A$ & 2978 & 29913 & 2006 \\
\hline B & $\begin{array}{l}\text { Qingdao / } \\
\text { Cold Zones }\end{array}$ & $4 \mathrm{~A}$ & 1991 & 44870 & 2006 \\
\hline C & $\begin{array}{l}\text { Hong Kong } \\
\text { /Hot Summer } \\
\text { Warm Winter }\end{array}$ & 2 & 4782 & 118000 & 2008 \\
\hline D & $\begin{array}{l}\text { Hong Kong } \\
\text { /Hot Summer } \\
\text { Warm Winter }\end{array}$ & 2 & 4782 & 26961 & 2003 \\
\hline$E$ & $\begin{array}{c}\text { Beijing / } \\
\text { Cold Zones }\end{array}$ & $4 \mathrm{~A}$ & 2274 & 30300 & 1990 \\
\hline
\end{tabular}

Table 2 Summary of the envelope properties of the investigated buildings

\begin{tabular}{cccc}
\hline Buildings & $\begin{array}{c}\text { Exterior wall U-factor } \\
\mathbf{W} /\left(\mathrm{m}^{2} . \mathrm{K}\right)\end{array}$ & $\begin{array}{c}\text { Window U-factor } \\
\mathbf{W} /\left(\mathrm{m}^{2} . \mathrm{K}\right)\end{array}$ & $\begin{array}{c}\text { Window Shading } \\
\text { Coefficient }(\mathrm{SC})\end{array}$ \\
\hline A & 1.0 & 2.5 & East/South/West: \\
\hline
\end{tabular}


North: 0.5

\begin{tabular}{cccc}
\hline B & 0.6 & 2.7 & 0.7 \\
\hline C & 1.03 & 1.6 & 0.19 \\
\hline D & 0.75 & 1.99 & 0.26 \\
\hline E & 0.6 & 3.0 & North/West: 0.81 \\
& & & East/North: 0.87 \\
\hline
\end{tabular}

Table 3 Summary of the HVAC systems of the investigated buildings

\begin{tabular}{ccccc}
\hline Buildings & $\begin{array}{c}\text { HVAC system } \\
\text { type }\end{array}$ & $\begin{array}{c}\text { Terminal unit } \\
\text { type }\end{array}$ & Control type & $\begin{array}{c}\text { Design } \\
\text { load } \\
\left(\mathbf{W} / \mathbf{m}^{2} \mathbf{)}\right.\end{array}$ \\
\hline A & $\begin{array}{c}\text { VRF heat } \\
\text { pump }\end{array}$ & VRF indoor unit & $\begin{array}{c}\text { Occupants control indoor units } \\
\text { individually; building operators } \\
\text { control outdoor units }\end{array}$ & 144 \\
\hline B & $\begin{array}{c}\text { VRF heat } \\
\text { pump }\end{array}$ & VRF indoor unit & $\begin{array}{c}\text { Occupants control indoor units } \\
\text { individually; building operators } \\
\text { control outdoor units }\end{array}$ & 105 \\
\hline C & Multiple VAVs & VAV box & $\begin{array}{c}\text { Centralized controlled by building } \\
\text { operators }\end{array}$ & 277 \\
\hline D & Multiple VAVs & VAV box & $\begin{array}{c}\text { Centralized controlled by building } \\
\text { operators }\end{array}$ & 195 \\
\hline E & Multiple VAVs & VAV box & $\begin{array}{c}\text { Centralized controlled by building } \\
\text { operators }\end{array}$ & 151 \\
\hline
\end{tabular}

\subsection{Site Survey}

Two sets of survey questionnaires were developed and conducted on site to better understand the actual behavior of the building operators and the occupants in the five buildings (as shown in Figure 3). One set of questionnaires targeted the operators by using questions on building envelope characteristics, air conditioning systems, and operation strategies. The other set targeted the occupants using questions on occupancy, lighting, equipment, ventilation, air conditioning temperature set point, and operation. Because the investigated VAV buildings 
were centrally operated by building operators, and the occupants did not have access to controls, the questionnaires for occupants were not administered in these buildings.

The survey was conducted in the summer of 2012. For each building, questionnaires were sent to the facility manager, who assigned the questionnaire to the building operators (all five buildings) and contacted a few tenants that were available to answer the questionnaire of the occupants (the two VRF buildings). Six floors with 333 occupants were surveyed in Building $A$ and nine rooms with 72 occupants were surveyed in Building B. The questionnaires were collected for further analysis. The survey results were used in conjunction with the collected measurement data to analyze and understand the differences between VRF and VAV systems.

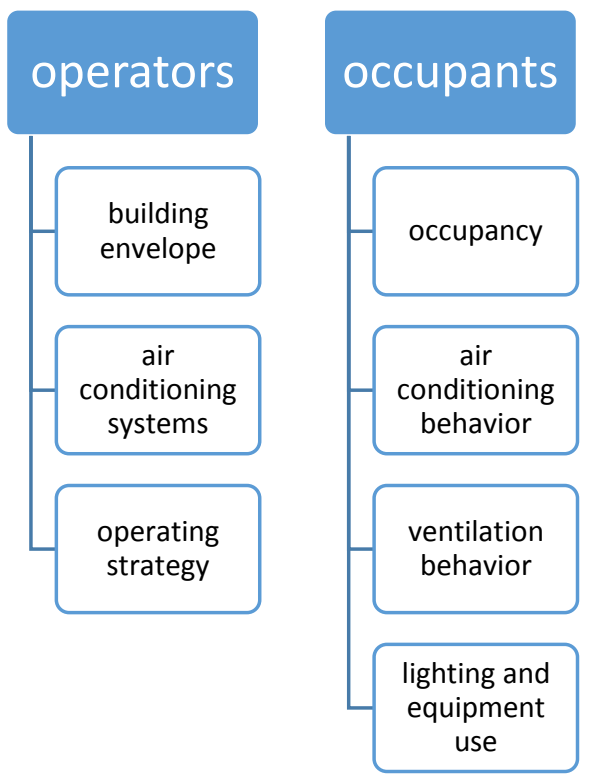

Figure 3 Site survey of the building operators and occupants

\subsection{Field measurements and sub-metered data}

The rapid development of automatic metering technology has led to the widespread installation of sub-metering systems of commercial buildings in China to track energy use. Building Management Systems (BMSs), which are an integrated management systems of building equipment monitoring and public safety, have been installed in cases where better building management and controls were sought. The three investigated VAV buildings (C, D, and $E$ ) were all equipped with the sub-metering system as well as the BMS system. The two VRF buildings ( $A$ and $B$ ) monitored and recorded the energy use by the VRF system's built-in energy monitoring system.

In this study, hourly energy consumption data of the air conditioning systems were collected from the sub-metering system and the BMS (see Figure 5 as an example). Figure 4 illustrates all the data that was collected and measured in this study. Additionally, indoor environmental conditions (including indoor air temperature, humidity, and $\mathrm{CO} 2$ concentration), internal heat gains (including lighting and equipment power density), and occupant behaviors (including 
turning on/off the HVAC and opening/closing windows) were all measured in a few offices of each of the five buildings. The measurements lasted about a month for each building. Table 4 lists the instruments that were used in the field measurements. The temperature and humidity loggers and $\mathrm{CO}_{2}$ loggers were placed on the desks within occupant activity area. The window status loggers were attached to the frames and opening edges of the windows.

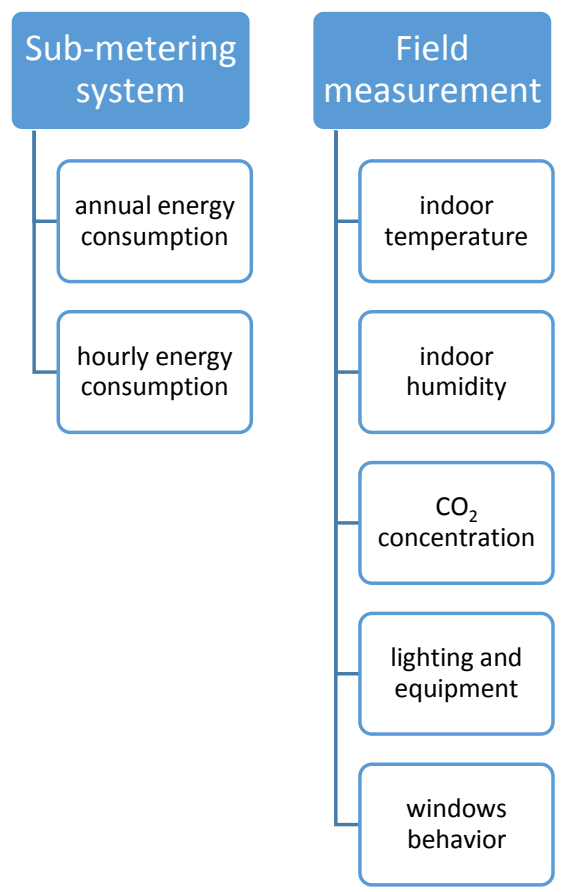

Figure 4 Data collection from the field measurement and sub-metering system

Table 4 Summary of the instruments used in the field measurement

\begin{tabular}{|c|c|c|c|}
\hline $\begin{array}{c}\text { Measurement } \\
\text { Instrument }\end{array}$ & $\begin{array}{c}\text { Temperature and } \\
\text { relative humidity (RH) }\end{array}$ & $\mathrm{CO}_{2}$ concentration & Window status \\
\hline Photo & $\begin{array}{c}\text { Measure and record the } \\
\text { temperature and } \\
\text { relative humidity } \\
\text { automatically }\end{array}$ & $\begin{array}{c}\text { Measure and } \\
\text { record the } \mathrm{CO}_{2} \\
\text { concentration } \\
\text { automatically }\end{array}$ & $\begin{array}{c}\text { Measure and record the } \\
\text { status (open or closed) of } \\
\text { the windows } \\
\text { automatically }\end{array}$ \\
\hline Rescription & Temperature: & $\begin{array}{c}\mathrm{CO}_{2} \text { concentration: } \\
\text { 0 5000ppm }\end{array}$ & $\begin{array}{c}\text { The maximum distance } \\
\text { between the sensors is }\end{array}$ \\
\hline
\end{tabular}




\begin{tabular}{|c|c|c|c|}
\hline & $\begin{array}{c}-40 \sim 100^{\circ} \mathrm{C} \\
\mathrm{RH}: 0 \sim 100 \%\end{array}$ & $\begin{array}{c}30 \mathrm{~mm} \text {. Result will either } \\
\text { be open or closed }\end{array}$ \\
\hline Uncertainty & $\begin{array}{c}\text { Temperature: } 0.1^{\circ} \mathrm{C} \\
\mathrm{RH}: 0.1 \%\end{array}$ & $\pm 75 \mathrm{ppm}$ & N/A \\
\hline
\end{tabular}

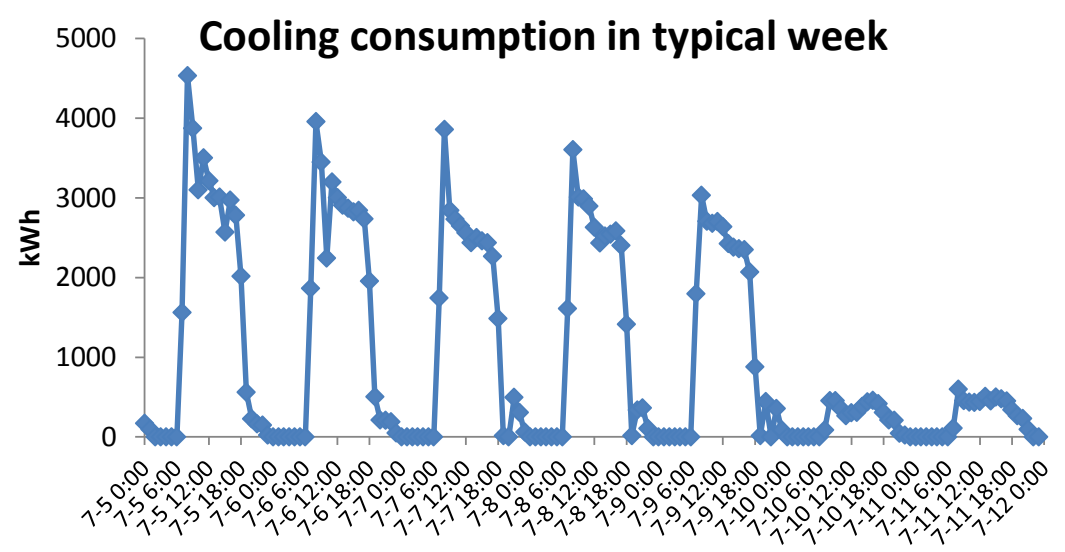

Figure 5 The measured cooling consumption of Building $E$ in a typical week

\subsection{Simulation}

The main factors that influenced the energy use discrepancy between VRF and VAV systems were identified based on the site surveys and field measurements. However, building simulations were required to quantify the sensitivity and influence of each factor. The designer's simulation toolkit (DeST) was developed by Tsinghua University in China in the early 1990s for practical research and use of building simulation. DeST was designed to simulate and analyze the energy consumption of both buildings and HVAC systems. Its aims included improving the system design reliability, ensuring system performance quality, and reducing building energy consumption. The main modules include a multi-zone heat and mass balance calculation based on the state space method [43], a three-dimensional dynamic heat transfer calculation, a dynamic coupling of CFD with hourly building simulation, and a system simulation considering uncertainty of internal heat gains. The accuracy of the DeST simulation results was validated using three methods: analytical verification, inter-program comparison based on ASHRAE Standard 140, and empirical validation [29]. In the study, DeST was chosen as the simulation tool because it had a built-in database of building materials, internal heat gains, HVAC systems, and operation controls for commercial buildings in China.

Figure 6 illustrates the simulation approach adopted in this study. A reference model with representative inputs for office buildings, including building envelopes, and internal heat gains and infiltration rates was developed in DeST. The key impact factors, including operation 
strategy and control mode were set differently for the VRF and VAV systems. Two representative climate zones for the five investigated buildings were selected so that the influence of the key factors could be analyzed under different weather conditions. Finally, the simulated cooling loads of the VRF and VAV systems were compared. The cooling loads came directly from the demand side by considering the impact of the operation mode, but excluding the system side impact of the efficiency of the VRF and VAV systems.
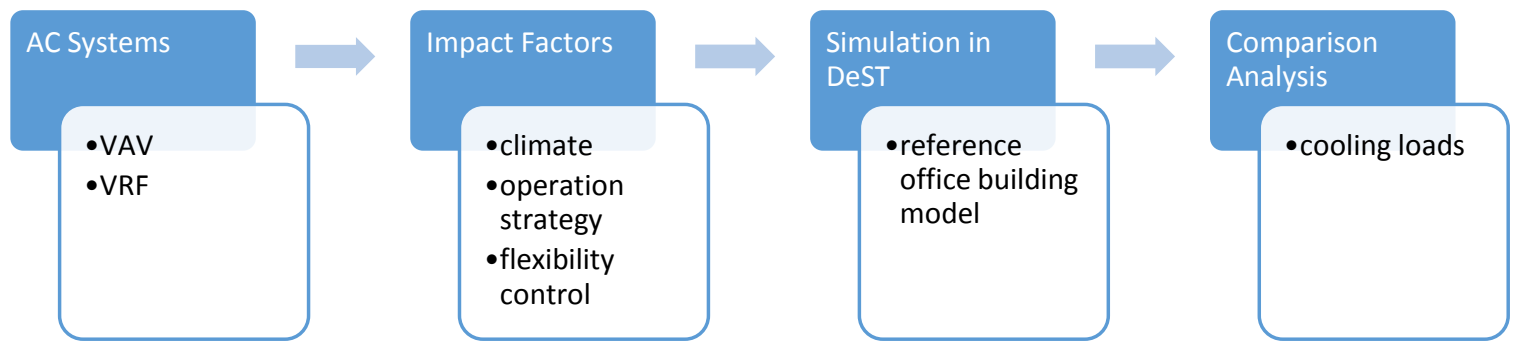

Figure 6 The Simulation Approach

\section{Results of the field measurements}

\subsection{Cooling Energy Consumption}

As shown in Figure 7, the field measurements of the five office buildings indicated that the annual energy consumptions of the air conditioning systems were significantly different. Buildings $A$ and $B$ with VRF systems as depicted by the left two bars in Figure 7 consumed significantly less cooling electricity than buildings $C, D$ and $E$ with VAV systems as indicated by the three right bars in Figure 7.



Figure 7 The Annual cooling energy consumption for the VRF and VAV systems $\left(\mathrm{kWh} / \mathrm{m}^{2}\right.$ of floor area) 
The investigated buildings were located in four cities belonging to different climate zones in China. Figure 8 shows the annual outdoor temperatures of the four cities. The cooling seasons of the four cities were quite different. Particularly, the average outdoor temperature in Hong Kong was much higher than those of the other three cities. This could significantly influence the energy consumption of the HVAC systems.

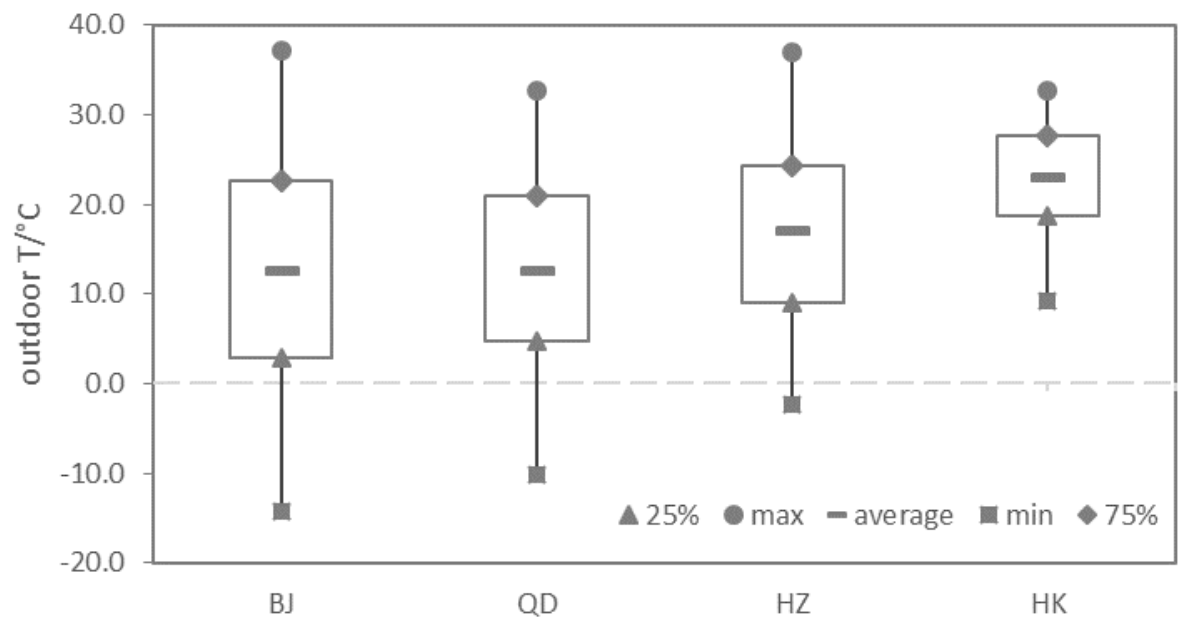

Figure 8 Statistics of the annual hourly outdoor air temperature

In order to normalize the impact of climate, the energy consumption values were normalized by dividing by the cooling degree days (CDDs) of the specific climate. This is referred to as the normalization method of climate in Energy Star [44], which uses the cooling degree days (CDDs) and heating degree days (HDDs) as the climate indices for normalization. In Figure 9, the normalized cooling energy consumption still shows significant discrepancies between the VRF and VAV systems.

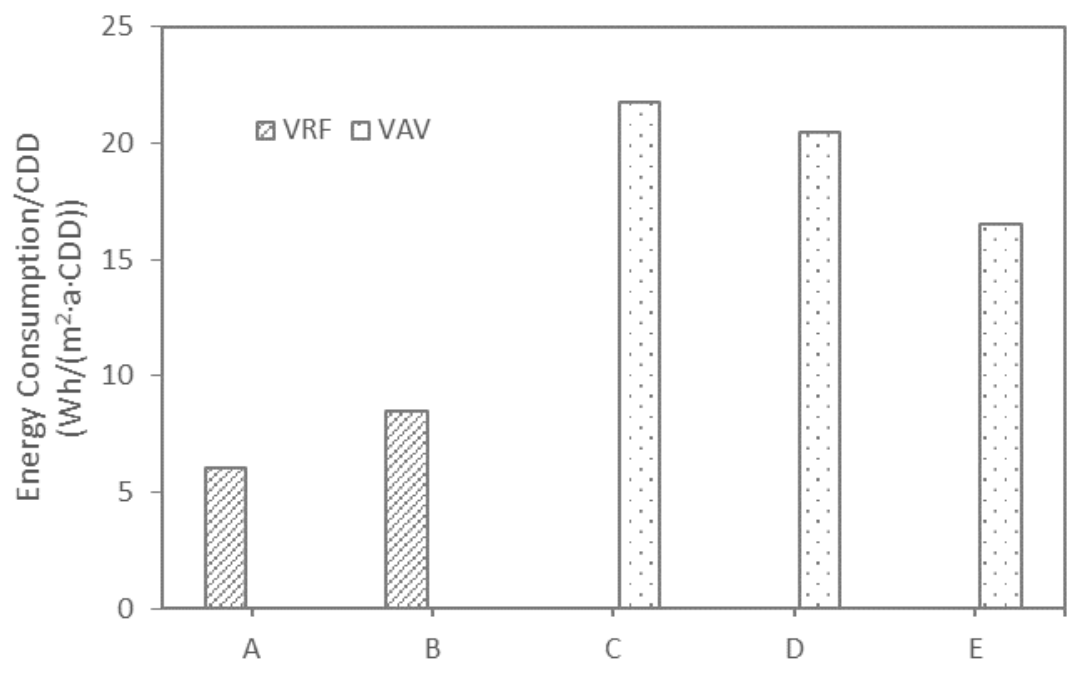

Figure 9 Normalized cooling energy consumption with respect to cooling degree days 
In a manner similar to the climate diversity, the occupant schedules of the buildings were slightly different. That is, the occupants generally worked for five and a half days per week in Hong Kong. In contrast, the building occupants in Beijing, Hangzhou, and Qingdao only worked for five days. In this case, the CDD normalized energy consumption was further divided by the number of working days, which was five and a half days for Hong Kong and five days for the other three cities. This normalized energy consumption was still significantly diverse as shown in Figure 10.



Figure 10 Occupant schedule normalized cooling energy consumption

\subsection{Influencing Factors}

Figure 10 indicates that the normalized energy use of the VAV systems was still more than twice the energy use of the VRF systems in the investigated buildings. Therefore, in addition to the climate and occupant schedule, other factors also led to the energy use discrepancy. The results from the site surveys and field measurements were thus analyzed to unveil the key influencing factors.

\subsubsection{Internal heat gains}

Internal heat gains greatly contributed to the cooling loads and energy consumption, including occupant density, lighting power density, as well as equipment power density. According to field-measured data in the study (shown in Table 5), the average occupant density in the five office buildings was almost the same at approximately 0.09 person $/ \mathrm{m}^{2}$. With respect to the lighting and equipment power density, the average lighting and equipment density was as high as $28 \mathrm{~W} / \mathrm{m}^{2}$ in Buildings $C$ and $D$ in Hong Kong, and exceeded 15 to $18 \mathrm{~W} / \mathrm{m}^{2}$ in buildings in Hangzhou, Qingdao, and Beijing. 
The office buildings in Hong Kong tended to have higher lighting requirements and considerably more office equipment leading to higher internal heat gains when compared to office buildings in mainland China. These differences in the internal heat gains were not necessarily related to the use of different HVAC system types.

It was revealed by comparing Building $\mathrm{E}$ (VAV system in Beijing) to Buildings A and B (VRF system in Hangzhou and Qingdao) that the internal loads were similar but the cooling energy use differed by up to $175 \%$ (Figure 10). Therefore, internal heat gains were not key factors leading to the discrepancies in cooling energy use.

Table 5 Average occupant density, lighting, and equipment power density of the five buildings

\begin{tabular}{|c|c|c|}
\hline & Buildings & Average \\
\hline \multirow{4}{*}{$\begin{array}{c}\text { Occupant density } \\
\text { (persons/m }\end{array}$} & $\mathrm{A}, \mathrm{HZ}$ & 0.09 \\
\cline { 2 - 3 } & $\mathrm{B}, \mathrm{QD}$ & 0.08 \\
\cline { 2 - 3 } & $\mathrm{C}, \mathrm{HK}$ & 0.08 \\
\cline { 2 - 3 } & $\mathrm{D}, \mathrm{HK}$ & 0.11 \\
\cline { 2 - 3 } & $\mathrm{E}, \mathrm{BJ}$ & 0.066 \\
\hline \multirow{2}{*}{$\begin{array}{c}\text { Lighting and } \\
\text { equipment power } \\
\text { density } \\
\left(\mathbf{W} / \mathbf{m}^{2}\right)\end{array}$} & $\mathrm{A}, \mathrm{HZ}$ & 15.3 \\
\cline { 2 - 3 } & $\mathrm{B}, \mathrm{QD}$ & 15.1 \\
\cline { 2 - 3 } & $\mathrm{C}, \mathrm{HK}$ & 28.6 \\
\cline { 2 - 3 } & $\mathrm{D}, \mathrm{HK}$ & 26.5 \\
\hline
\end{tabular}

\subsubsection{Operation and controls}

In addition to internal heat gains, another important factor that significantly influenced the energy consumption of the VAV and VRF systems was the system operation and control strategy, which was directly related to the building operators and occupants.

\subsubsection{Starting temperature and operating temperature}

Indoor environmental parameters, such as air temperature, humidity, and $\mathrm{CO}_{2}$ concentration, were measured in several offices of each investigated building. Figure 11 illustrates the measured indoor air temperature in two offices in Building B. Figure 12 illustrates the measured return air temperature of four VAV boxes in Building E. According to the measured indoor air temperature, there were significant fluctuations with noticeable crests and troughs in the indoor air temperature of the VRF systems (Figure 11). In contrast, the indoor air temperature of the VAV system was relatively stable (Figure 12). It was concluded from the site surveys that the crests occurred when occupants switched on the VRF indoor units, and that the troughs comprised the traditional comfort temperature set point. In the study, the average crest was defined as the "starting temperature" and the average trough was defined as the "operating temperature". The occupants turned on VRF indoor units when they felt hot and indoor air temperature reached the starting temperature. Once the VRF indoor units were on, they operated to maintain a comfort temperature called the operating temperature. The indoor 
units were turned off (e.g. for room 5 in Figure 11, air conditioning was turned off around 11 am) when the offices were not occupied. In the VRF systems, there were obvious patterns of starting temperatures and operating temperatures. Conversely, there were only patterns of operating temperatures found in the VAV systems. Based on the field measurement data of the indoor air temperature, the starting temperature and operating temperature of the VRF systems were determined to be approximately $28^{\circ} \mathrm{C}$ and $26^{\circ} \mathrm{C}$, respectively. The operating temperature of the VAV systems was usually approximately $24^{\circ} \mathrm{C}$.
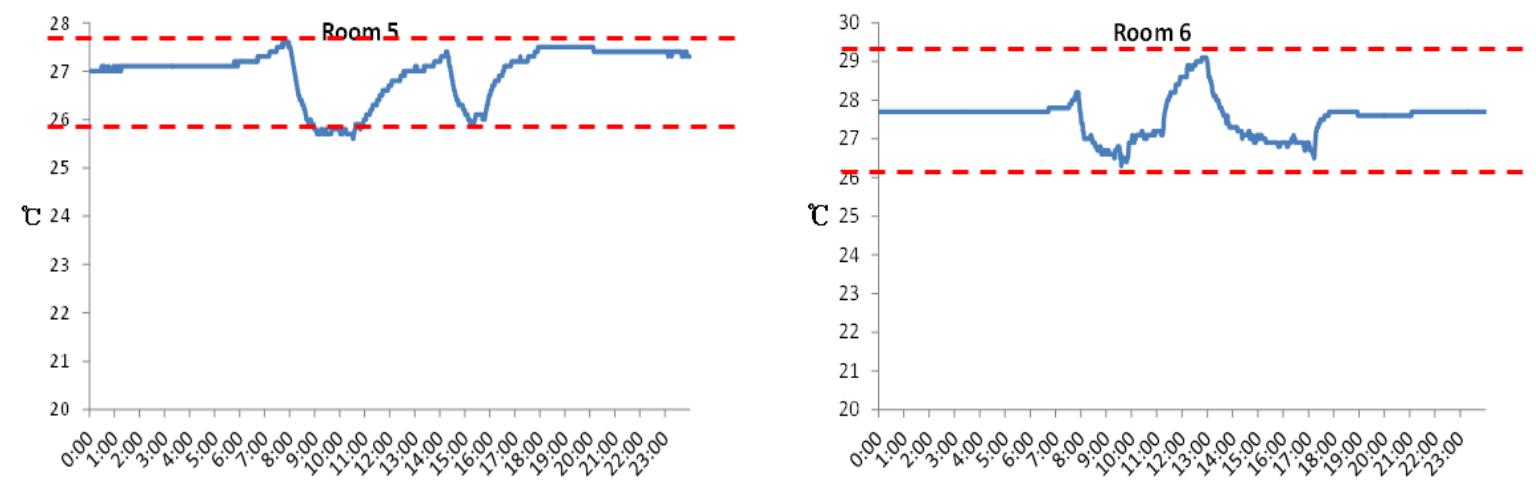

Figure 11 Measurement data of the indoor air temperature in Building B with VRF systems

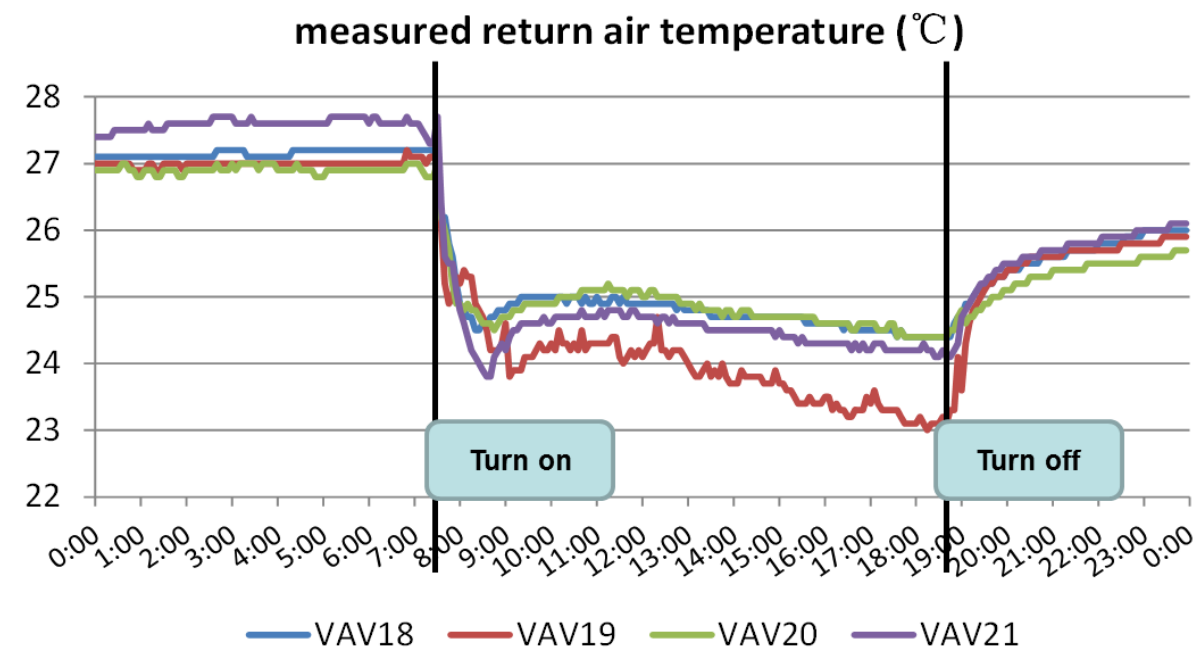

Figure 12 Measurement data of return air temperature of the selected VAV boxes in Building E with VAV systems

\subsubsection{Flexibility of individual control}

Moreover, the VRF indoor units were controlled by the individual occupants according to the survey results of the air conditioning operation modes, the ventilation patterns, and the air- 
conditioning temperature setpoints in the VRF systems shown in Table 6. This was different from the VAV systems that were centrally controlled by the building operator. In other words, the VRF systems were more flexible and personalized.

The different internal heat gains and thermal comfort demand led to three types of VRF operating modes in this study: (1) the AC was operated by a fixed schedule with no window opening; (2) the occupants preferred ventilation by opening windows, they only turned on the $A C$ when they felt hot, and the indoor air temperature reached the starting temperature; and (3) the $A C$ was rarely turned on, and the occupants usually opened the windows for ventilation. Outdoor air was provided in various ways in the VRF systems including dedicated centralized outdoor air handling units, dedicated indoor units, and infiltration.

With respect to the VAV systems, chillers were operated and maintained by specialized personnel. The centralized VAV air handling units (AHUs) only worked during the office hours and were controlled by operators with fixed schedules. Typically, centralized outdoor air was provided through the AHUs.

Table 6 The site survey of the operation modes of the VRF systems

\begin{tabular}{|c|c|c|c|c|c|}
\hline $\begin{array}{l}\text { Tenant } \\
\text { IDs }\end{array}$ & \multicolumn{3}{|c|}{ VRF operation modes } & $\begin{array}{l}\text { Temperature } \\
\text { setpoint }\left({ }^{\circ} \mathrm{C}\right)\end{array}$ & $\begin{array}{c}\text { Ventilation } \\
\text { when } A C \text { is on }\end{array}$ \\
\hline 1 & $\begin{array}{c}\text { Turn on } \\
\text { when } \\
\text { feeling hot }\end{array}$ & 1-3 hours per day & $\begin{array}{l}\text { Ventilation } \\
\text { when no } A C\end{array}$ & $25-27$ & no \\
\hline 2 & $\begin{array}{c}\text { Turn on } \\
\text { when } \\
\text { feeling hot }\end{array}$ & & $\begin{array}{l}\text { Ventilation } \\
\text { when no } A C\end{array}$ & 25 & no \\
\hline 3 & \multicolumn{3}{|c|}{ All day } & $23-24$ & no \\
\hline 4 & $\begin{array}{c}\text { Turn on } \\
\text { when } \\
\text { feeling hot }\end{array}$ & $\begin{array}{l}\text { usually turn on at } \\
\text { noon, off after work }\end{array}$ & $\begin{array}{l}\text { Ventilation } \\
\text { when no AC }\end{array}$ & 24 & no \\
\hline 5 & $\begin{array}{c}\text { Turn on } \\
\text { when } \\
\text { feeling hot }\end{array}$ & & $\begin{array}{l}\text { Ventilation } \\
\text { when no } A C\end{array}$ & $25-26$ & no \\
\hline 6 & \multicolumn{3}{|c|}{ All day } & $21-23$ & no \\
\hline 7 & \multicolumn{3}{|c|}{ All day } & $25-26$ & Sometimes \\
\hline 8 & $\begin{array}{c}\text { Almost no } \\
\text { AC }\end{array}$ & & $\begin{array}{c}\text { Always } \\
\text { ventilation }\end{array}$ & 25 & no \\
\hline 9 & $\begin{array}{c}\text { Turn on } \\
\text { when } \\
\text { feeling hot }\end{array}$ & rarely & $\begin{array}{c}\text { Ventilation } \\
\text { when no } A C\end{array}$ & 25 & no \\
\hline 10 & \multicolumn{3}{|c|}{ All day } & $19-23$ & occasionally \\
\hline
\end{tabular}




\subsubsection{Summary of operation and control characteristics}

The above analysis for on-site survey results and field measurement data revealed that the key impact factors leading to the energy use discrepancy between the VRF and VAV systems included the HVAC system operation characteristics and control strategy, such as the starting temperature, operating temperature, operation modes, adjustable range, and outdoor air units, as shown in Table 7.

Table 7 Key differences in operation and control between the VRF and VAV systems

\begin{tabular}{|c|c|c|}
\hline & VRF Systems & VAV Systems \\
\hline $\begin{array}{c}\text { Staring } \\
\text { temperature }\end{array}$ & Yes, about $28^{\circ} \mathrm{C}$ & No \\
\hline $\begin{array}{c}\text { Operating } \\
\text { temperature }\end{array}$ & $26^{\circ} \mathrm{C}$ & $24^{\circ} \mathrm{C}$ \\
\hline Operation Mode & $\begin{array}{c}\text { Controlled by the occupants, indoor } \\
\text { units are operated separately }\end{array}$ & Centralized control with fixed schedules \\
\hline Outdoor Air Units & Usually use natural ventilation & Centralized fresh air \\
\hline
\end{tabular}

In summary, the VRF systems operated in part-time-part-space decentralized mode where occupants turned on the cooling only when they felt hot. However, the VAV systems operated in full-time-full-space central mode for a much longer operating period.

\section{Simulation}

\subsection{Purpose of Simulation}

According to the aforementioned analysis, the key factors causing the huge discrepancy of energy use between the VRF and VAV systems were summarized. Theoretically, in order to quantify the sensitivity and the impact of individual factors, the VAV and VRF systems must be compared under identical conditions of climate/location, building shape, building envelope, and internal heat gains. As this is not feasible in reality, building simulations were employed to quantify the impact of the operation mode on the system performance.

A reference energy model with representative inputs for office buildings, such as building envelopes, internal heat gains and infiltration rates, was developed using DeST. The key impact factors included the operation strategy and control mode, and they were set differently for the VRF and VAV systems. Two typical climates from the five investigated locations were also selected to help in understanding the influence on performance by the climate. Lastly, the cooling loads of the VRF and VAV systems of the same reference office building were compared. The cooling loads came directly from the demand side by considering the impact of operation mode, but excluding the system side impact of efficiency of the VRF and VAV systems. In this way, comparing the cooling loads could isolate the impact of other factors but focus on the impact of the operation mode. 
A reference office building model was built up with all parameters set to the same values, except those using different operation modes of the VRF and VAV systems. This excluded the impact of climate, building shape, envelope properties, room functions, and internal heat gains

\subsection{Simulation Model}

\subsubsection{The prototype office building model}

As shown in Figure 13, the prototype office building model was a 22-floor tower building. The envelope properties were set according to the 2005 energy standards for public buildings in China, as shown in Table 8. As shown in Fig. 13 and Fig. 14, the occupant schedule, lighting schedule and equipment schedule were set similar to those of the investigated office buildings, based on a site survey.



Figure 13 The reference office building model

Table 8 Key parameters of the reference office building model

\begin{tabular}{|c|c|c|}
\hline & Item & Value \\
\hline \multirow{2}{*}{ Wall } & heat transfer coefficient $\left(\mathrm{W} / \mathrm{m}^{2} . \mathrm{K}\right)$ & 0.564 \\
\hline \multirow{2}{*}{ Window } & heat transfer coefficient $\left(\mathrm{W} / \mathrm{m}^{2} . \mathrm{K}\right)$ & 1.8 \\
\cline { 2 - 3 } & Shading coefficient & 0.45 \\
\hline \multicolumn{2}{|c|}{ Window-wall-ratio } & 0.6 \\
\hline \multicolumn{2}{|c|}{ Occupant density $\left(\mathbf{p} / \mathbf{m}^{\mathbf{2}}\right)$} & 0.089 \\
\hline \multicolumn{2}{|c|}{ Lighting power density $\left(\mathbf{W} / \mathbf{m}^{\mathbf{2}}\right)$} & 10.66 \\
\hline \multicolumn{2}{|c|}{ Equipment power density $\left(\mathbf{W} / \mathbf{m}^{\mathbf{2}}\right)$} & 16.85 \\
\hline
\end{tabular}




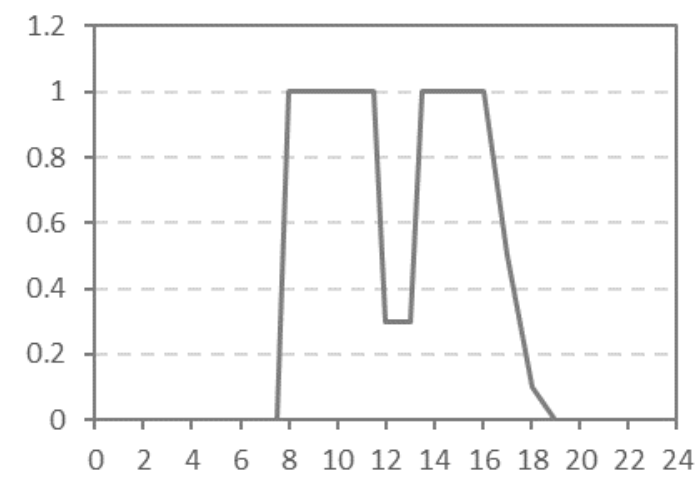

Figure 14 Occupant schedule in the reference model during weekdays

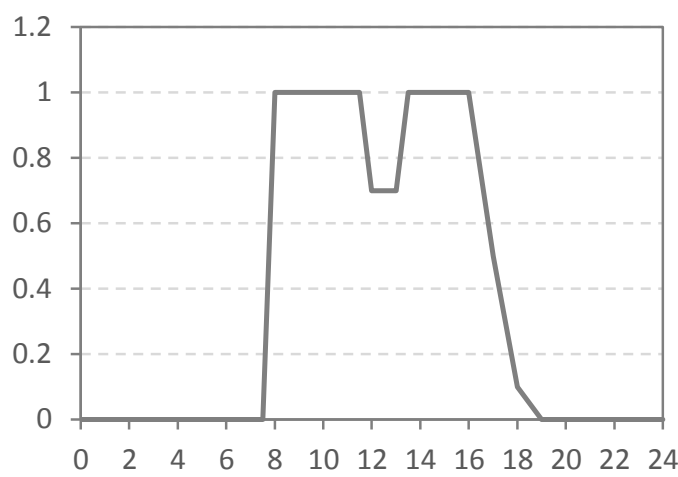

Figure 15 Lighting and equipment schedules in the reference model during weekdays

\subsubsection{Operational parameters of the VRF and VAV systems}

Operational parameters of the VAV and VRF systems based on the site survey and the measurements are summarized in Table 9 and Table 10, respectively. The operating schedules of the VAV systems were fixed and contained both an overtime work schedule and a no overtime work schedule. In comparison, the operating schedules of the VRF systems were more flexible, and according to the site survey results, there were three types related to indoor and outdoor conditions. Furthermore, the upper limit of the thermostat set points in the VAV systems was $24^{\circ} \mathrm{C}$. In contrast, it was $26^{\circ} \mathrm{C}$ in VRF systems.

The operation schedules and parameters were applied to the spaces in the prototype model according to their frequency from the site survey of the space operation conditions.

Table 9 The operational parameters of the VAV systems

\begin{tabular}{|c|c|}
\hline Item & Description \\
\hline \multirow{2}{*}{ AC operating schedule } & no overtime work: 8:00 19:00 \\
\cline { 2 - 3 } & overtime work: 8:00 22:00 \\
\hline Thermostat setpoints & $20 \sim 24^{\circ} \mathrm{C}$ \\
\hline Humidity setpoints & $35 \% \sim 70 \% \mathrm{RH}$ \\
\hline Outdoor air & $30 \mathrm{~m}^{3} / \mathrm{h}$. person \\
\hline
\end{tabular}

Table 10 Operational parameters of the VRF systems

\begin{tabular}{|c|c|c|c|c|}
\hline $\begin{array}{c}\text { Room } \\
\text { type }\end{array}$ & System operating schedule & $\begin{array}{c}\text { Operating } \\
\text { Temperature } \\
\left({ }^{\circ} \mathrm{C}\right)\end{array}$ & $\begin{array}{c}\text { Starting } \\
\text { Temperature } \\
\left({ }^{\circ} \mathrm{C}\right)\end{array}$ & $\begin{array}{c}\text { Outdoor air } \\
\text { flow rate }\end{array}$ \\
\hline 1 & no overtime work: 8:00-19:00 & 26 & No & $\begin{array}{c}30 \\
\mathrm{~m}^{3} / \mathrm{h} . \text { person }\end{array}$ \\
\cline { 2 - 5 } & with overtime work: 8:00-22:00 & No & $\leq 5 \mathrm{ACH}$ \\
\hline 2 & Ventilation only, no AC & 28 & $\begin{array}{c}30 \\
\mathrm{~m}^{3} / \mathrm{h} . \text { person }\end{array}$ \\
\hline 3 & $\begin{array}{c}\text { Turn on VRF only when indoor air } \\
\text { temperature exceeds the starting }\end{array}$ & 26 & 28 & \\
\hline
\end{tabular}




\begin{tabular}{|c|c|c|c|c|}
\hline & $\begin{array}{c}\text { temperature, and natural ventilation } \\
\text { can't satisfy comfort need. }\end{array}$ & & & \\
\cline { 2 - 4 } & $\begin{array}{c}\text { If natural ventilation can satisfy } \\
\text { comfort need, turn off VRF }\end{array}$ & & & $\leq 5 \mathrm{ACH}$ \\
\cline { 2 - 5 }
\end{tabular}

\subsection{Quantitative Analysis}

A quantitative analysis was performed for two cities representing two typical climates in China, Qingdao and Hong Kong, given that the cooling loads under the different climates may vary significantly.

According to the simulation results (Figure 16 and Figure 17), the buildings with the VRF system operation mode had 53\% and 42\% lower cooling loads in Qingdao and Hong Kong, respectively than the buildings with the VAV system operation mode.

Evidently, the cooling loads of the VRF systems or the VAV systems in Hong Kong were significantly larger than those in Qingdao. This was mainly due to the characteristics of the climates. Qingdao has a summer cooling season that lasts for five months, while Hong Kong's cooling season is year-round. The mild outdoor temperature in Qingdao enabled more use of natural ventilation to replace mechanical cooling, which helped in reducing the cooling loads as well.

The two key factors that the quantitative analysis attempted to address were the operational parameters, operation mode and indoor temperature setpoint. The results in Figure 16 and Figure 17 show the overall impact of the two factors. Their individual impacts were also simulated and analyzed. The results indicated an approximately equal influence by the operation mode and the indoor temperature setpoint. 


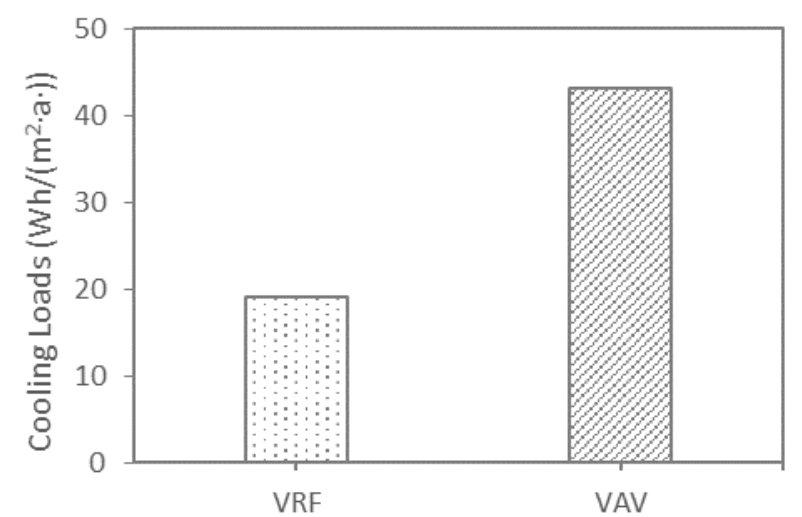

Figure 16 Simulated cooling loads of the VRF and VAV systems in Qingdao

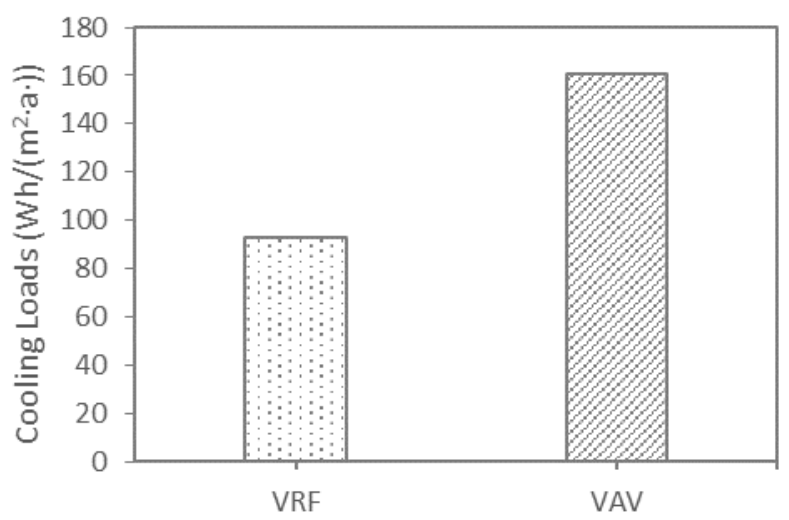

Figure 17 Simulated cooling loads of the VRF and VAV systems in Hong Kong

\subsection{Summary}

It can be concluded that the two key factors, namely operation mode and indoor temperature setpoint, resulted in the VRF systems with as much as $42 \%$ less cooling loads than the VAV systems in Hong Kong, and 53\% less cooling loads in Qingdao.

\section{Discussion}

The VRF systems consumed much less energy than the VAV systems mainly due to the flexibility of operation and controls. The part-time-part-space operation mode of the VRF systems allowed occupants to turn on the air conditioner only when required and occupied. This resulted in much shorter operation time. In contrast, the full-time-full-space operation mode of the VAV systems operated with a fixed schedule, and this was less flexible (that is, the VAV boxes could not be turned off even when a space did not need air-conditioning) and led to a much longer operation time. Moreover, the VRF systems had a wider range for capacity adjustment and the occupants could turn off the air conditioner whenever they did not need it, which improved the thermal comfort.

Conversely, the VAV systems had the advantages of centralized installation and maintenance, while the spidery nature of the VRF pipework and specific installation requirements limited the application of VRF systems in some particular cases. Special tools and techniques were essential to tighten flare joints and minimize the risk of leakage during the installation of the VRF systems. Additionally, VAV systems with air economizers were able to provide "free cooling" when the outdoor temperature was lower than the recirculation air temperature. In comparison, VRF systems usually recirculated indoor air and required separate outdoor air units to provide the code defined minimum ventilation, and were thus unable to make full use of "free cooling". However, the occupants in China could open windows in most cases to ventilate and cool buildings with VRF systems, thereby providing the equivalent effect of "free cooling". 
Besides, according to the interview results of the occupants' indoor thermal environment satisfaction, both VRF and VAV systems can competently meet the demands. In other words, the VRF systems offer almost same thermal comfort services as the VAV systems while consuming less energy.

Generally, VRF and VAV systems have advantages as well as disadvantages. The high flexibility of VRF systems significantly contributed to thermal comfort and energy savings. As a result, VRF systems were more suitable for buildings in part-time-part-space operation mode with high flexibility when a refrigerant pipework could be installed.

In the investigated VRF buildings, three operation modes were observed, as discussed in Section 3. The energy consumption of the VRF systems was the result of all three modes combined. The case when the VRF systems were controlled by a single operation mode was considered. The differences between the three modes were estimated by assigning each single operation mode to the reference energy model. The simulation results indicated that the operation mode with the starting temperatures could reduce cooling loads by $18 \%$, when compared to the operation mode with the fixed schedule. In comparison, the operation mode with only natural ventilation did not consume cooling energy.

It should be noted that the study had limitations: (1) all five investigated buildings were located in China, and hence the findings were primarily applicable to buildings in China; however, the methodology of site survey, field measurement, analysis and simulation was generic and applicable to buildings in other countries; (2) the number of investigated buildings was limited (mainly due to the requirement of detailed site survey, measurement, and sub-metering), and thus more samples will be needed in future research to provide more comprehensive data for more detailed comparisons; (3) ideally buildings in the same location/climate but with different VRF and VAV systems would help eliminate the influence of weather on building energy use by simplifying the performance comparison.

\section{Conclusion}

VRF systems consumed much less energy than VAV systems in office buildings in China, by mainly benefiting from their flexibility of operation and controls. It was found that the VRF systems' part-time-part-space operation mode allowed occupants to turn on the cooling only when required and when the spaces were occupied. In contrast, the VAV systems' full-time-fullspace operation mode did not allow occupants to turn off the cooling, and resulted in much longer operation time and thereby consumed much more energy.

There are many factors to consider in the HVAC design to determine system type and operation strategy. However, enabling individual control by the occupants in decentralized systems like VRF could improve the comfort and save energy when compared with centralized systems like VAV. These new findings provide insights into the actual system performance and operation of the two most typical air conditioning systems used in office buildings in China, which can help 
guide HVAC system designers and building operators to improve system selection and operation strategy to help achieve low- or zero-net energy buildings.

Future work can include a comprehensive economic analysis to compare performance of both system types from the life cycle cost perspective.

\section{Acknowledgments}

This research was funded by the Engineering and Physical Sciences Research Council (EPSRC) grant (EP/N009703/1) and the National Natural Science Foundation of China (NSFC) grant (51561135001) for the Total Performance of Low Carbon Buildings in China and the UK, and Innovative Research Groups of the National Natural Science Foundation of China (grant number 51521005). It was also supported by Daikin-Tsinghua Joint Research Center and the Assistant Secretary of the Office of Energy Efficiency \& Renewable Energy of the U.S. Department of Energy under Contract No. DE-AC02-05CH11231 through the U.S.-China joint program of Clean Energy Research Center on Building Energy Efficiency.

\section{References}

[1] IEA, Key World Energy Statistics, Ar.Newsmth.Net. (2009). http://ar.newsmth.net/att/633efe465236a/Key_World_Energy_Statistics(2007).pdf.

[2] L. Pérez-Lombard, J. Ortiz, C. Pout, A review on buildings energy consumption information, Energy Build. 40 (2008) 394-398. doi:10.1016/j.enbuild.2007.03.007.

[3] A. Costa, M.M. Keane, J.I. Torrens, E. Corry, Building operation and energy performance: Monitoring, analysis and optimisation toolkit, Appl. Energy. 101 (2013) 310-316. doi:10.1016/j.apenergy.2011.10.037.

[4] C. Peng, D. Yan, S. Guo, S. Hu, Y. Jiang, Building energy use in China: Ceiling and scenario, Energy Build. 102 (2015) 307-316. doi:10.1016/j.enbuild.2015.05.049.

[5] L. Yang, H. Yan, J.C. Lam, Thermal comfort and building energy consumption implications - A review, Appl. Energy. 115 (2014) 164-173. doi:10.1016/j.apenergy.2013.10.062.

[6] L. Peeters, R. de Dear, J. Hensen, W. D’haeseleer, Thermal comfort in residential buildings: Comfort values and scales for building energy simulation, Appl. Energy. 86 (2009) 772-780. doi:10.1016/j.apenergy.2008.07.011.

[7] T.N.T. Lam, K.K.W. Wan, S.L. Wong, J.C. Lam, Impact of climate change on commercial sector air conditioning energy consumption in subtropical Hong Kong, Appl. Energy. 87 (2010) 2321-2327. doi:10.1016/j.apenergy.2009.11.003.

[8] J.C. Lam, K.K.W. Wan, K.L. Cheung, An analysis of climatic influences on chiller plant electricity consumption, Appl. Energy. 86 (2009) 933-940. doi:10.1016/j.apenergy.2008.05.016.

[9] W. Chung, Review of building energy-use performance benchmarking methodologies, Appl. Energy. 88 (2011) 1470-1479. doi:10.1016/j.apenergy.2010.11.022. 
[10] K.P. Lam, R. Zhang, H. Wang, B. Dong, R. Zhang, Development of web-based information technology infrastructures and regulatory repositories for green building codes in China (iCodes), Build. Simul. 6 (2013) 195-205. doi:10.1007/s12273-013-0112-0.

[11] K.K.W. Wan, D.H.W. Li, W. Pan, J.C. Lam, Impact of climate change on building energy use in different climate zones and mitigation and adaptation implications, Appl. Energy. 97 (2012) 274-282. doi:10.1016/j.apenergy.2011.11.048.

[12] Y. Yao, Z. Lian, W. Liu, Z. Hou, M. Wu, Evaluation program for the energy-saving of variable-air-volume systems, Energy Build. 39 (2007) 558-568.

doi:10.1016/j.enbuild.2006.09.010.

[13] S.A. Mumma, R.J. Bolin, Energy optimized-ventilation constrained variable air volume system control, Autom. Constr. 6 (1997) 463-470. doi:10.1016/S0926-5805(97)00024-1.

[14] F. Engdahl, D. Johansson, Optimal supply air temperature with respect to energy use in a variable air volume system, Energy Build. 36 (2004) 205-218.

doi:10.1016/j.enbuild.2003.09.007.

[15] M. Hydeman, S. Taylor, J. Stein, E. Kolderup, T. Hong, Advanced Variable Air Volume System Design Guide, V (2009).

http://energydesignresources.com/resources/publications/design-guidelines/designguidelines-advanced-variable-air-volume-(vav)-systems.aspx.

[16] G.Y. Yun, J.H. Lee, H.J. Kim, Development and application of the load responsive control of the evaporating temperature in a VRF system for cooling energy savings, Energy Build. 116 (2016) 638-645. doi:10.1016/j.enbuild.2016.02.012.

[17] K.J. Chua, S.K. Chou, W.M. Yang, J. Yan, Achieving better energy-efficient air conditioning - A review of technologies and strategies, Appl. Energy. 104 (2013) 87-104. doi:10.1016/j.apenergy.2012.10.037.

[18] T.N. Aynur, Variable refrigerant flow systems: A review, Energy Build. 42 (2010) 11061112. doi:10.1016/j.enbuild.2010.01.024.

[19] R. Karunakaran, S. Iniyan, R. Goic, Energy efficient fuzzy based combined variable refrigerant volume and variable air volume air conditioning system for buildings, Appl. Energy. 87 (2010) 1158-1175. doi:10.1016/j.apenergy.2009.08.013.

[20] B.W. Goetzler, M. Ashrae, Variable refrigerant flow systems, ASHRAE J. (2007) 24-31. doi:10.1016/j.enbuild.2010.01.024.

[21] Y.P. Zhou, J.Y. Wu, R.Z. Wang, S. Shiochi, Energy simulation in the variable refrigerant flow air-conditioning system under cooling conditions, Energy Build. 39 (2007) 212-220. doi:10.1016/j.enbuild.2006.06.005.

[22] X. Liu, T. Hong, Comparison of energy efficiency between variable refrigerant flow systems and ground source heat pump systems, Energy Build. 42 (2010) 584-589. doi:10.1016/j.enbuild.2009.10.028.

[23] L.E. Southard, X. Liu, J.D. Spitler, Performance of HVAC systems at ASHRAE HQ, ASHRAE J. 
56 (2014) 12-23.

[24] T.N. Aynur, Y. Hwang, R. Radermacher, Simulation comparison of VAV and VRF air conditioning systems in an existing building for the cooling season, Energy Build. 41 (2009) 1143-1150. doi:10.1016/j.enbuild.2009.05.011.

[25] Y.M. Li, J.Y. Wu, S. Shiochi, Experimental validation of the simulation module of the water-cooled variable refrigerant flow system under cooling operation, Appl. Energy. 87 (2010) 1513-1521. doi:10.1016/j.apenergy.2009.09.018.

[26] K.W. Roth, J. Dieckmann, S.D. Hamilton, W. Goetzler, Energy Consumption Characteristics of Commercial Building HVAC Systems Volume III : Energy Savings Potential, Build. Technol. Progr. III (2002).

[27] Y. Zhu, X. Jin, Z. Du, X. Fang, B. Fan, Control and energy simulation of variable refrigerant flow air conditioning system combined with outdoor air processing unit, Appl. Therm. Eng. 64 (2014) 385-395. doi:10.1016/j.applthermaleng.2013.12.076.

[28] Y. Zhu, X. Jin, Z. Du, B. Fan, S. Fu, Generic simulation model of multi-evaporator variable refrigerant flow air conditioning system for control analysis, Int. J. Refrig. 36 (2013) 1602-1615. doi:10.1016/j.ijrefrig.2013.04.019.

[29] T.N. Aynur, Y. Hwang, R. Radermacher, Field Performance Measurements of a Vrv Ac / Hp System, Int. Refrig. Air Cond. Conf. (2006) 1-8.

[30] A.-T. Nguyen, S. Reiter, P. Rigo, A review on simulation-based optimization methods applied to building performance analysis, Appl. Energy. 113 (2014) 1043-1058. doi:10.1016/j.apenergy.2013.08.061.

[31] K. Sun, T. Hong, S.C. Taylor-Lange, M.A. Piette, A pattern-based automated approach to building energy model calibration, Appl. Energy. 165 (2016) 214-224. doi:10.1016/j.apenergy.2015.12.026.

[32] Y.P. Zhou, J.Y. Wu, R.Z. Wang, S. Shiochi, Y.M. Li, Simulation and experimental validation of the variable-refrigerant-volume (VRV) air-conditioning system in EnergyPlus, Energy Build. 40 (2008) 1041-1047. doi:10.1016/j.enbuild.2007.04.025.

[33] Y. Li, J. Wu, S. Shiochi, Modeling and energy simulation of the variable refrigerant flow air conditioning system with water-cooled condenser under cooling conditions, Energy Build. 41 (2009) 949-957. doi:10.1016/j.enbuild.2009.04.002.

[34] T. Hong, K. Sun, R. Zhang, R. Hinokuma, S. Kasahara, Y. Yura, Development and validation of a new variable refrigerant flow system model in EnergyPlus, Energy Build. (2015). doi:10.1016/j.enbuild.2015.09.023.

[35] D. Yan, J. Xia, W. Tang, F. Song, X. Zhang, Y. Jiang, DeST - An integrated building simulation toolkit Part I: Fundamentals, Build. Simul. 1 (2008) 95-110. doi:10.1007/s12273-008-8118-8.

[36] X.L. Zhang, J.J. Xia, Z.Y. Jiang, J.Y. Huang, R. Qin, Y. Zhang, et al., DeST-An Integrated Building Simulation Toolkit Part.: Applications, Build. Simul. 1 (2008) 193-209. 
doi:10.1007/s12273-008-8124-x.

[37] X. Zhou, T. Hong, D. Yan, Comparison of HVAC system modeling in EnergyPlus, DeST and DOE-2.1E, Build. Simul. 7 (2014) 21-33. doi:10.1007/s12273-013-0150-7.

[38] D. Zhu, T. Hong, D. Yan, C. Wang, A detailed loads comparison of three building energy modeling programs: EnergyPlus, DeST and DOE-2.1E, Build. Simul. 6 (2013) 323-335. doi:10.1007/s12273-013-0126-7.

[39] X. Wang, J. Xia, X. Zhang, S. Shiochi, C. Peng, Y. Jiang, Modeling and experiment analysis of variable refrigerant flow air-conditioning systems, Elev. Int. IBPSA Conf. (2009) 361368.

[40] D. Yan, W. O’Brien, T. Hong, X. Feng, H. Burak Gunay, F. Tahmasebi, et al., Occupant behavior modeling for building performance simulation: Current state and future challenges, Energy Build. 107 (2015) 264-278. doi:10.1016/j.enbuild.2015.08.032.

[41] K. Sun, D. Yan, T. Hong, S. Guo, Stochastic modeling of overtime occupancy and its application in building energy simulation and calibration, Build. Environ. 79 (2014) 1-12. doi:10.1016/j.buildenv.2014.04.030.

[42] C. Wang, D. Yan, Y. Jiang, A novel approach for building occupancy simulation, Build. Simul. 4 (2011) 149-167. doi:10.1007/s12273-011-0044-5.

[43] T. Hong, Y. Jiang, A new multizone model for the simulation of building thermal performance, Build. Environ. 32 (1997) 123-128. doi:10.1016/S0360-1323(96)00045-5.

[44] EnergyStar, Technical Reference Climate and Weather, (2013) 1-10.

\section{Nomenclature}

\begin{tabular}{|llll|}
\hline VAV & Variable air volume & SC & Shading coefficient \\
VRF & Variable refrigerant flow & BMS & Building management system \\
DeST & Designer's simulation toolkit & RH & Relative humidity \\
CDDs & Cooling degree days & AHUs & Air handling units \\
HDDs & Heating degree days & EEVs & Electronic expansion valves \\
\hline
\end{tabular}




\begin{tabular}{|llll|}
\hline GSHP & Ground source heat pump & ppm & parts per million \\
CFD & Computational Fluid Dynamics & HVAC & $\begin{array}{l}\text { Heating, ventilation, and air- } \\
\text { conditioning }\end{array}$ \\
\hline
\end{tabular}

